Journal of Advanced Research in Fluid Mechanics and Thermal Sciences

Journal homepage: www.akademiabaru.com/arfmts.html ISSN: 2289-7879

\title{
Lower Stagnation Point Flow of Convectively Heated Horizontal Circular Cylinder in Jeffrey Nanofluid with Suction/Injection
}

\author{
Syazwani Mohd Zokri ${ }^{1}$, Mohd Zuki Salleh ${ }^{1,}{ }^{*}$, Nur Syamilah Arifin ${ }^{2}$, Abdul Rahman Mohd Kasim ${ }^{1}$ \\ 1 Centre for Mathematical Sciences, College for Computing and Applied Sciences, Universiti Malaysia Pahang, 26300 Kuantan, Pahang, Malaysia \\ Universiti Teknologi MARA, Cawangan Johor, Kampus Pasir Gudang, 81750 Masai, Johor, Malaysia
}

\section{ARTICLE INFO ABSTRACT}

\section{Article history:}

Received 13 April 2020

Received in revised form 25 August 2020

Accepted 2 September 2020

Available online 9 October 2020

\section{Keywords:}

Lower stagnation point; Jeffrey nanofluid; convective boundary conditions; suction/injection; mixed convection

\begin{abstract}
Lower stagnation point flow of Jeffrey nanofluid from a horizontal circular cylinder is addressed under the influences of suction/injection, mixed convection and convective boundary conditions. Copper $(\mathrm{Cu})$ is taken as the nanoparticles while Carboxymethyl cellulose (CMC) water is taken as the base fluid. The transformed boundary layer equations through the non-dimensional variables and non-similarity transformation variables are subsequently tackled by means of the Runge-Kutta Fehlberg method (RKF 45). The impact of dimensionless parameters such as the suction/injection, nanoparticles volume fraction and Deborah number are graphically presented and discussed in detail. The outcomes reveal that the velocity and temperature profiles are both augmented with rising values of nanoparticles volume fraction. Velocity profile escalates as suction/injection parameter rises but declines as Deborah number upsurges. Temperature profile reduces when suction/injection parameter enlarges and augments when Deborah number increases.
\end{abstract}

Copyright @ 2020 PENERBIT AKADEMIA BARU - All rights reserved

\section{Introduction}

Fluid suction or injection through the bounding surface can substantially modify the flow field and also affect the surface heat transfer rate. According to Al-Sanea [1], enhancement in skin friction and heat transfer coefficients is perceived as a result of suction while injection acts contradictorily. Besides, fluid injection via a porous heated or cooled surface can improve the heating or cooling of the system and also assist the postponement of fluid transition from laminar flow [2].

Exploration of the non-Newtonian fluid models is a topic of ample research due to their diverse nature and industrial and engineering applications such as crystal growing, polymeric melt, dilute

\footnotetext{
${ }^{*}$ Corresponding author.

E-mail address: zuki@ump.edu.my

https://doi.org/10.37934/arfmts.76.1.135
} 
polymer solutions, cosmetic products, drilling muds, foods, glass blowing and coated sheets. Various constitutive relationships have been established in the previous works to exhibit the complex features of non-Newtonian fluids. Such establishment stems from the fact that the imperative characteristic of non-Newtonian fluids is incapable to be analyzed by the classical equations of Navier-Stokes, which is only usable to assess the Newtonian fluid features. A number of latest interesting studies concerning non-Newtonian fluids may be retrieved from the works of Arifin et al., [3], Zokri et al., [4], Mustafa et al., [5], Kumar et al., [6] and Ashraf et al., [7]. The model of nonNewtonian Jeffrey fluid has been proven quite efficacious for its capability in determining the viscoelasticity property of materials, namely the dual components of retardation and relaxation times. An example of this fluid model as mentioned by Hayat et al., [8] is dilute polymer solution.

Nevertheless, non-Newtonian fluids are well-known to unable fulfill the requirements of high intensity heat transfer because of their unsatisfactory thermal conductivity. The theory of suspending the nanoparticles such as metallic, non-metallic or polymeric nano-sized powders into the nonNewtonian fluid has been one of the contemporary innovative ideas in recent years to increase the thermal conductivity as well as enhance the heat transfer performance. These suspensions are called as nanofluid and are of size lesser than $100 \mathrm{~nm}$. Due to unique physical and chemical properties, nanofluid has been widely used in transportation industry, electronic application (microelectromechanical systems and cooling of microchips), pharmaceutical processes and biomedical (nano-cryosurgery, nano-drug delivery, cryopreservation and cancer therapeutics). An experimental work carried out by Choi and Eastman [9] has revealed that the features of the base fluid had momentously enhanced due to the dispersion of nanoparticles. This groundbreaking work has prompted the researchers to inspect the involvement of nanofluids in various conventional fluids, geometries and amalgamation of several effects. Pal and Mandal [10] analyzed the mutual impacts of microrotation and nanoparticle together with non-uniform heat source/sink, thermal radiation, suction and magnetic field. They examined four kinds of nanoparticles, for instance silver, alumina, copper and titania. Lu et al., [11] addressed the nonlinear thermal radiation effect in micropolar fluid suspended with nanoparticles and induced by a nonlinear vertical stretching sheet. The influences of magnetohydrodynamics, mixed convection and heat generation/absorption under the convectively heated boundary conditions were accounted. Also, the Ferric Oxide $\left(\mathrm{Fe}_{3} \mathrm{O}_{4}\right)$ nanoparticles in the water-based micropolar nanofluid is investigated. Very recently, Kumam et al., [12] presented the applications of entropy generation for single-walled carbon nanotubes (SWCNTs) and multi-walled carbon nanotubes (MWCNTs) based on kerosene oil for Casson nanofluid flow from a rotating channel. The outcome of the study was tackled by means of the homotopic approach.

Interest in fluid flow passing through a horizontal circular cylinder with mixed convection has been revealed through a number of publications ever since the work of Merkin [13]. Extension of his problem was carried out by Aldoss et al., [14] and Aldos and Ali [15] who incorporated the impacts of MHD and suction and blowing, respectively. Then, Nazar et al., [16] and Nazar et al., [17] inspected the flow of micropolar fluid by taking into account of the constant wall temperature and constant heat flux cases, respectively, while the viscoelastic fluid flow with constant wall temperature was analyzed by Anwar et al., [18]. In the following year, the impact of temperature-dependent viscosity was explored by Ahmad et al., [19] while the Newtonian heating condition was assimilated by Salleh et al., [20] in a viscous fluid. By utilizing the nanofluid model proposed by Tiwari and Das, Nazar et al., [21] inspected three kinds of nanoparticles such as $\mathrm{Cu}, \mathrm{Al}_{2} \mathrm{O}_{3}$ and $\mathrm{TiO}_{2}$ and water-based fluid. Shortly after, Tham et al., [22] continued the study by examining the porous medium effect. The problem scrutinized by Anwar et al., [18] was prolonged by Kasim et al., [23] to the constant heat flux. Mohamed et al., [24] and Mohamed et al., [25] examined the viscous dissipation effect in the respective viscous and nanofluid model with constant wall temperature. Zokri et al., [26] 
implemented the Buongiorno model to investigate the Jeffrey nanofluid model with viscous dissipation effect. Very recently, Mahat et al., [27] adopted the Tiwari and Das model to examine the copper and Carboxymethyl cellulose (CMC) water in viscoelastic nanofluid model.

Driven by the discussions pointed out above, it is clear that the Jeffrey nanofluid flow passing through horizontal circular cylinder has so far never been investigated using the Tiwari and Das model. Therefore, it is imperative to explore the impacts of mixed convection, suction/injection and convective boundary condition on lower stagnation point flow of Jeffrey nanofluid from a horizontal circular cylinder. Here, the Carboxymethyl cellulose (CMC) water represents based fluid while copper signifies nanoparticles. The closely related existing publications were from Zokri et al., [26] and Mahat et al., [27].

\section{Mathematical Formulation}

Suppose a Jeffrey fluid flow suspended with nanoparticles towards a horizontal circular cylinder in the presence of suction/injection and mixed convection is scrutinized. Figure 1 demonstrates the cylinder of radius $a$, being heated to a convective boundary conditions with ambient temperature $T_{\infty}$ The $\bar{x}$ and $\bar{y}$ coordinates of the cylinder surface are measured starting from the lower stagnation point $\bar{x}=0$ and perpendicular to it, respectively. Then, the relevant equations governing the flow are:

$\frac{\partial \bar{u}}{\partial \bar{x}}+\frac{\partial \bar{v}}{\partial \bar{y}}=0$

$\rho_{n f}\left(\bar{u} \frac{\partial \bar{u}}{\partial \bar{x}}+\bar{v} \frac{\partial \bar{u}}{\partial \bar{y}}\right)=\rho_{n f} \bar{u}_{e} \frac{d \bar{u}_{e}}{\partial \bar{x}}+\frac{\mu_{n f}}{(1+\lambda)}\left[\frac{\partial^{2} \bar{u}}{\partial \bar{y}^{2}}+\lambda_{1}\left(\bar{u} \frac{\partial^{3} \bar{u}}{\partial \bar{x} \partial \bar{y}^{2}}+\bar{v} \frac{\partial^{3} \bar{u}}{\partial \bar{y}^{3}}-\frac{\partial \bar{u}}{\partial \bar{x}} \frac{\partial^{2} \bar{u}}{\partial \bar{y}^{2}}+\frac{\partial \bar{u}}{\partial \bar{y}} \frac{\partial^{2} \bar{u}}{\partial \bar{x} \partial \bar{y}}\right)\right]+$ $g\left(\rho \beta_{T}\right)_{n f}\left(T-T_{\infty}\right) \sin \frac{\bar{x}}{a}$,

$$
\left(\rho C_{p}\right)_{n f}\left(\bar{u} \frac{\partial T}{\partial \bar{x}}+\bar{v} \frac{\partial T}{\partial \bar{y}}\right)=k_{n f} \frac{\partial^{2} T}{\partial \bar{y}^{2}},
$$

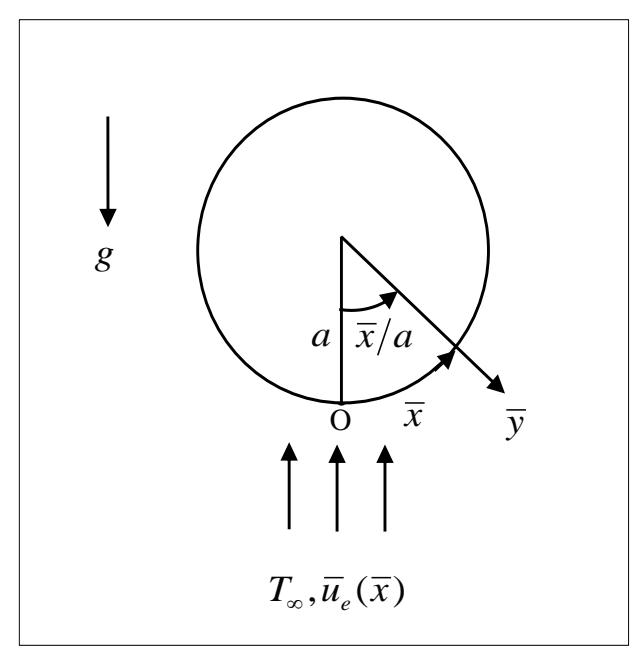

Fig. 1. Physical model of the coordinate system 
where the density of nanofluid, thermal expansion coefficient of nanofluid, heat capacity of nanofluid, effective viscosity of nanofluid and effective thermal conductivity of nanofluid are symbolized as $\rho_{n f},\left(\rho \beta_{T}\right)_{n f},\left(\rho C_{p}\right)_{n f}, \mu_{n f}$ and $k_{n f}$, respectively and defined as follows

$\rho_{n f}=(1-\phi) \rho_{f}+\phi \rho_{s}, \quad\left(\rho \beta_{T}\right)_{n f}=(1-\phi)\left(\rho \beta_{T}\right)_{f}+\phi\left(\rho \beta_{T}\right)_{s}, \quad\left(\rho C_{p}\right)_{n f}=(1-\phi)\left(\rho C_{p}\right)_{n f}+$ $\phi\left(\rho C_{p}\right)_{s}$

$\mu_{n f}=\frac{\mu_{f}}{(1-\phi)^{2.5}}, k_{n f}=k_{f} \frac{\left(k_{s}+2 k_{f}\right)-2 \phi\left(k_{f}-k_{s}\right)}{\left(k_{s}+2 k_{f}\right)+\phi\left(k_{f}-k_{s}\right)}$

The appropriate boundary conditions are

$\bar{u}(\bar{x}, 0)=0, \bar{v}(\bar{x}, 0)=V_{w,}-k_{f} \frac{\partial T}{\partial \bar{y}}=h_{f}\left(T_{f}-T\right)$ at $\bar{y}=0$

$\bar{u}(\bar{x}, \infty) \rightarrow \bar{u}_{e}, \bar{v}(\bar{x}, \infty) \rightarrow 0, T(\bar{x}, \infty) \rightarrow T_{\infty}$ as $\bar{y} \rightarrow \infty$

where $\bar{u}$ and $\bar{v}$ are the velocity components along the $\bar{x}$ and $\bar{y}$ axes, respectively, $T$ is the fluid temperature, $\lambda$ is the ratio of relaxation to retardation times, $\lambda_{1}$ is the retardation time, $g$ is the gravity acceleration, $\phi$ is the nanoparticle volume fraction of nanofluid, $V_{w}$ is the uniform suction or injection velocity, $h_{f}$ is the heat transfer coefficient, $T_{f}$ is the hot fluid, $k_{f}$ is the thermal conductivity and $\bar{u}_{e}(x)$ is the external velocity, denoted as

$\bar{u}_{e}(x)=U_{\infty} \sin \left(\frac{\bar{x}}{a}\right)$

where $U_{\infty}$ is the free stream velocity. Table 1 presents the thermophysical properties of the base fluid and nanoparticles. The carboxymethyl cellulose (CMC) water is used as the non-Newtonian base fluid, as suggested by Lin et al., [28]. CMC-water exhibits shear thinning or pseudoplastic rheological behavior and has been experimentally proven to be one of the common types of time-independent non-Newtonian fluid [29].

Table 1

Thermophysical properties of base fluid and nanoparticles

\begin{tabular}{lllll}
\hline Physical properties & $\rho\left(\mathrm{kg} \mathrm{m}^{-3}\right)$ & $C_{p}\left(\mathrm{~kg}^{-1} \mathrm{~K}^{-1}\right)$ & $k\left(\mathrm{~W} \mathrm{~m}^{-1} \mathrm{~K}^{-1}\right)$ & $\beta_{T} \times 10^{5}\left(\mathrm{~K}^{-1}\right)$ \\
\hline Base fluid (CMC) & 997.1 & 4179 & 0.613 & 21 \\
Nanoparticle (Cu) & 8933 & 385 & 401 & 1.67 \\
\hline
\end{tabular}

Now, the following non-dimensional variables are imposed to reduce the dimensional governing Eq. (1)-(3) to dimensionless form:

$x=\frac{\bar{x}}{a}, y=\operatorname{Re}^{\frac{1}{2} \frac{\bar{y}}{a}}, u=\frac{\bar{u}}{U_{\infty}}, v=\operatorname{Re}^{\frac{1}{2}} \frac{\bar{v}}{U_{\infty}}, \theta=\frac{T-T_{\infty}}{T_{f}-T_{\infty}}, u_{e}=\frac{\bar{u}_{e}}{U_{\infty}}$

Then, the dimensionless form of governing equations is

$\frac{\partial u}{\partial x}+\frac{\partial v}{\partial y}=0$ 
$u \frac{\partial u}{\partial x}+v \frac{\partial v}{\partial y}=u_{e} \frac{d u_{e}}{d x}+\frac{1}{(1-\phi)^{2.5}\left(1-\phi+\phi\left(\rho_{s} / \rho_{f}\right)\right)(1+\lambda)}$

$\left[\frac{\partial^{2} u}{\partial y^{2}}+\lambda^{2}\left(u \frac{\partial^{3} u}{\partial x \partial y^{2}}+\bar{v} \frac{\partial^{3} u}{\partial y^{3}}-\frac{\partial u}{\partial x} \frac{\partial^{2} u}{\partial y^{2}}+\frac{\partial u}{\partial y} \frac{\partial^{2} u}{\partial x \partial y}\right)\right]+\frac{1-\phi+\phi\left(\left(\rho \beta_{T}\right)_{s} /\left(\rho \beta_{T}\right)_{f}\right)}{1-\phi+\phi\left(\rho_{s} / \rho_{f}\right)} \gamma \theta \sin x$,

$u \frac{\partial \theta}{\partial x}+v \frac{\partial \theta}{\partial y}=\frac{k_{n f} / k_{f}}{1-\phi+\phi\left(\left(\rho C_{p}\right)_{s} /\left(\rho C_{p}\right)_{f}\right)} \frac{1}{P r} \frac{\partial^{2} \theta}{\partial y^{2}}$

with the related boundary conditions

$u(x, 0)=0, v(x, 0)=\frac{V_{w} R e_{x}^{\frac{1}{2}}}{U_{\infty}}, \frac{\partial \theta}{\partial y}(x, 0)=-B i(1-\theta(x, 0))$ at $y=0$

$u(x, \infty) \rightarrow u_{e}, v(x, \infty) \rightarrow 0,0(x, \infty) \rightarrow 0$ as $y \rightarrow \infty$

where $\lambda_{2}=\frac{\lambda_{1} U_{\infty}}{a}, \operatorname{Pr}=\left(\frac{C_{p} \mu}{k}\right)_{f}, \gamma=\frac{G r_{x}}{R e_{x}^{2}}, G r_{x}=\frac{g \beta_{T}\left(T_{f}-T_{\infty}\right) a^{3}}{v_{f}^{2}}$ and $R e_{x}=\frac{U_{\infty} a}{v_{f}}$ are the respective Deborah number, Prandtl number, mixed convection parameter, Grashof number and Reynolds number. Following Merkin [13], Eq. (7)-(9) are solved by seeking the succeeding non-similarity transformation variables

$\psi=x f(x, y), \theta=\theta(x, y)$

where $\psi$ is the stream function, denoted as $u=\frac{\partial \psi}{\partial y}$ and $v=-\frac{\partial \psi}{\partial x}$ and $\theta$ is the rescaled dimensionless temperature of fluid. Now, Eq. (7) is identically satisfied while Eq. (8) and Eq. (9) produce

$\frac{1}{(1-\phi)^{2.5}(1+\lambda)}\left[\frac{\partial^{3} f}{\partial y^{3}}+\lambda_{2}\left(\left(\frac{\partial^{2} f}{\partial y^{2}}\right)^{2}-f \frac{\partial^{4} f}{\partial y^{4}}\right)\right]+C_{1}\left(f \frac{\partial^{2} f}{\partial y^{2}}-\left(\frac{\partial f}{\partial y}\right)^{2}\right)+C_{2} \frac{\sin x}{x} \gamma \theta+C_{1} \frac{\sin x \cos x}{x}=$

$x C_{1}\left[\frac{\partial f}{\partial y} \frac{\partial^{2} f}{\partial x \partial y}-\frac{\partial f}{\partial x} \frac{\partial^{2} f}{\partial y^{2}}+\frac{\lambda_{2}}{C_{1}(1-\phi)^{2.5}(1+\lambda)}\left(\frac{\partial f}{\partial x} \frac{\partial^{4} f}{\partial y^{4}}-\frac{\partial f}{\partial y} \frac{\partial^{4} f}{\partial x \partial y^{3}}+\frac{\partial^{2} f}{\partial x \partial y} \frac{\partial^{3} f}{\partial y^{3}}-\frac{\partial^{2} f}{\partial y^{2}} \frac{\partial^{3} f}{\partial x \partial y^{2}}\right)\right]$,

$\frac{1}{P r} \frac{k_{n f}}{k_{f}} \frac{\partial^{2} \theta}{\partial y^{2}}+C_{3} f \frac{\partial \theta}{\partial y}=x C_{3}\left(\frac{\partial f}{\partial y} \frac{\partial \theta}{\partial x}-\frac{\partial f}{\partial x} \frac{\partial \theta}{\partial y}\right)$

with $C_{1}, C_{2}$ and $C_{3}$ are constants and be defined as

$C_{1}=1-\phi+\phi \frac{\rho_{s}}{\rho_{f}}, C_{2}=1-\phi+\phi \frac{\left(\rho \beta_{T}\right)_{s}}{\left(\rho \beta_{T}\right)_{f}}, C_{3}=1-\phi+\phi \frac{\left(\rho C_{p}\right)_{s}}{\left(\rho C_{p}\right)_{f}}$

and the boundary conditions Eq. (10) become

$f(x, 0)=f_{w}, \frac{\partial f}{\partial y}(x, 0)=0, \frac{\partial \theta}{\partial y}(x, 0)=-B i(1-\theta(x, 0))$ at $y=0$

$\frac{\partial f}{\partial y}(x, \infty) \rightarrow \frac{\sin x}{x}, \frac{\partial^{2} \theta}{\partial y^{2}}(x, \infty) \rightarrow 0, \theta(x, \infty) \rightarrow 0$ as $y \rightarrow \infty$

Eq. (12) and Eq. (13) give rise to the succeeding ordinary differential equations at lower stagnation region, $x \approx 0$ 
$\frac{1}{(1-\phi)^{2.5}(1+\lambda)}\left[\frac{\partial^{3} f}{\partial y^{3}}+\lambda_{2}\left(\left(\frac{\partial^{2} f}{\partial y^{2}}\right)^{2}-f \frac{\partial^{4} f}{\partial y^{4}}\right)\right]+C_{1}\left(f \frac{\partial^{2} f}{\partial y^{2}}-\left(\frac{\partial f}{\partial y}\right)^{2}\right)+C_{2} \gamma \theta+C_{1}=0$,

$\frac{1}{\operatorname{Pr}} \frac{k_{n f}}{k_{f}} \frac{\partial^{2} \theta}{\partial y^{2}}+C_{3} f \frac{\partial \theta}{\partial y}=0$

with the boundary conditions

$$
\begin{aligned}
& f(0)=f_{w}, \frac{\partial f}{\partial y}(0)=0, \frac{\partial \theta}{\partial y}(0)=-B i(1-\theta(0)) \\
& \frac{\partial f}{\partial y}(\infty) \rightarrow 1, \frac{\partial^{2} f}{\partial y^{2}}(\infty) \rightarrow 0, \theta(\infty) \rightarrow 0
\end{aligned}
$$

where $f_{w}=-\frac{V_{w} R e_{x}^{\frac{1}{2}}}{U_{\infty}}$ is the suction/injection and $B i=-\frac{h_{f} a}{k_{f} R e_{x}^{\frac{1}{2}}}$ is the Biot number.

\section{Results and Discussion}

The outcomes of several physical parameters such as suction/injection parameter $f_{w}$, nanoparticle volume fraction $\phi$ and Deborah number $\lambda_{2}$ are examined graphically over the velocity and temperature profiles. A numerical method named Runge-Kutta Fehlberg method (RKF 45) encoded in Maple software is applied to obtain the solution for nonlinear ordinary differential Eq. (15) and Eq. (16) together with boundary conditions of Eq. (17). The numerical values are taken as follows: $\lambda=\phi=\gamma=0.1, \lambda_{2}=f_{w}=0.2, \operatorname{Pr}=6.2$ and $B i=0.5$. Table 2 demonstrates the comparison between the results generated through this endeavor and existing works by Merkin [13], Nazar et al., [16], Rashad et al., [30] and Zokri et al., [26] for dissimilar values of $\gamma$. The values are perceived to be in an outstanding agreement, hence validating the obtained graphical results as revealed later.

Importance of physical parameters $f_{w}, \phi$ and $\lambda_{2}$ on velocity and temperature profiles is elucidated via Figure 2 to Figure 7. It is noticed from Figure 2 that the thickness of velocity boundary layer shrinkages with rising values of suction parameter, $f_{w}>0$. This is due to the fact that, suction effect tends to remove the fluid from the system, thereby diminishes the thickness of momentum boundary layer. In contrast, injection effect, $f_{w}<0$ permits the fluid to go into the system which subsequently thickens the velocity boundary layer thickness. Furthermore, as perceived in Figure 3 , the thermal boundary layer thickness is intensified when $f_{w}<0$, while it lessened when $f_{w}>0$.

Figure 4 and Figure 5 present the effect of dissimilar $\phi$ values on both velocity and temperature. With increasing $\phi$ from 0 to 0.5 , the velocity profile is seen to be accelerating owing to the augmentation of the energy transport. Besides, the increase of thermal boundary layer thickness is very much connected with the incremented thermal conductivity of the nanofluid. This increment is supplemented by larger values of thermal diffusivity that aid in reducing the temperature gradients and subsequently, increase the thickness of thermal boundary layer. 


\section{Table 2}

Comparative values of $-\theta^{\prime}(0)$ with preceding publications for dissimilar values of $\gamma$ when $\lambda=$ $\phi=0, \operatorname{Pr}=1$ and $\lambda_{2} \rightarrow 0$ (very small)

\begin{tabular}{|c|c|c|c|c|c|}
\hline \multicolumn{6}{|c|}{$-\theta^{\prime}(0)$} \\
\hline$\gamma$ & Merkin [13] & Nazar et al., [16] & Rashad et al., [30] & Zokri et al., [26] & Present \\
\hline-1 & 0.5067 & 0.5080 & 0.5068 & 0.506679 & 0.506678 \\
\hline-0.5 & 0.5420 & 0.5430 & 0.5421 & 0.542072 & 0.542065 \\
\hline 0 & 0.5705 & 0.5710 & 0.5706 & 0.570484 & 0.570470 \\
\hline 0.5 & 0.5943 & 0.5949 & 0.5947 & 0.594546 & 0.594534 \\
\hline 0.88 & 0.6096 & 0.6112 & 0.6111 & 0.610775 & 0.610762 \\
\hline 0.89 & 0.6110 & 0.6116 & 0.6114 & 0.611182 & 0.611169 \\
\hline 1 & 0.6158 & 0.6160 & 0.6160 & 0.615601 & 0.615587 \\
\hline 2 & 0.6497 & 0.6518 & 0.6518 & 0.651507 & 0.651492 \\
\hline 5 & 0.7315 & 0.7320 & 0.7319 & 0.731529 & 0.731510 \\
\hline
\end{tabular}

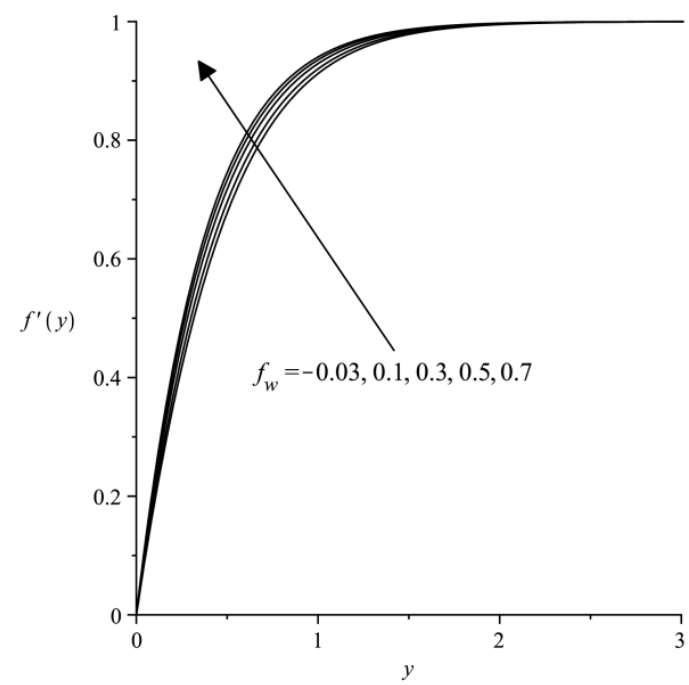

Fig. 2. Variation of $f^{\prime}(y)$ due to $f_{w}$

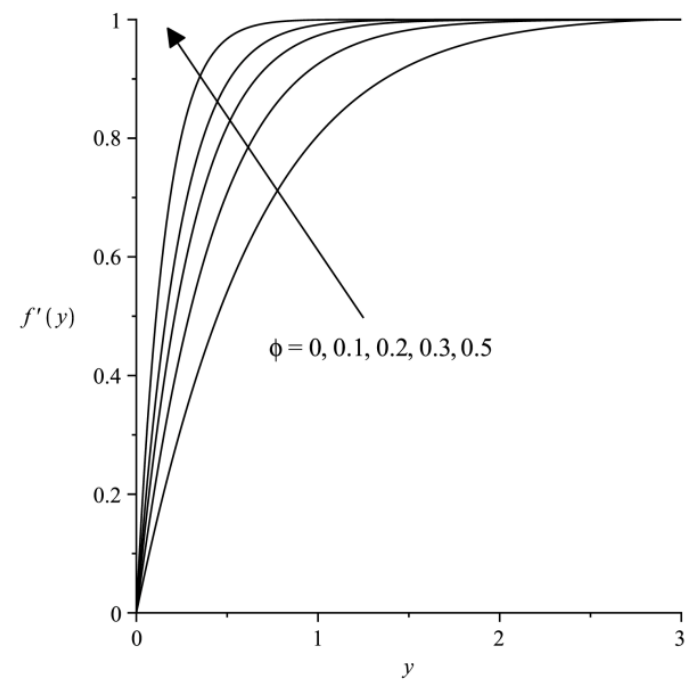

Fig. 4. Variation of $f^{\prime}(y)$ due to $\phi$

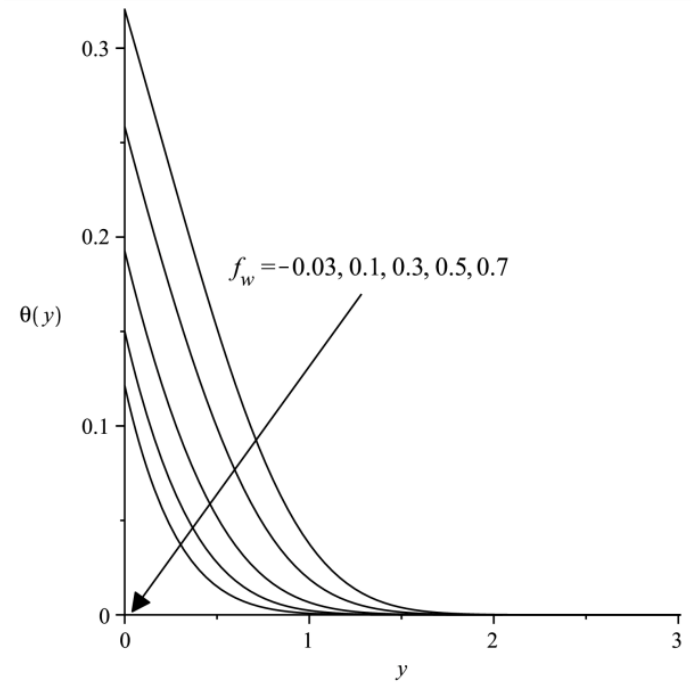

Fig. 3. Variation of $\theta(y)$ due to $f_{w}$

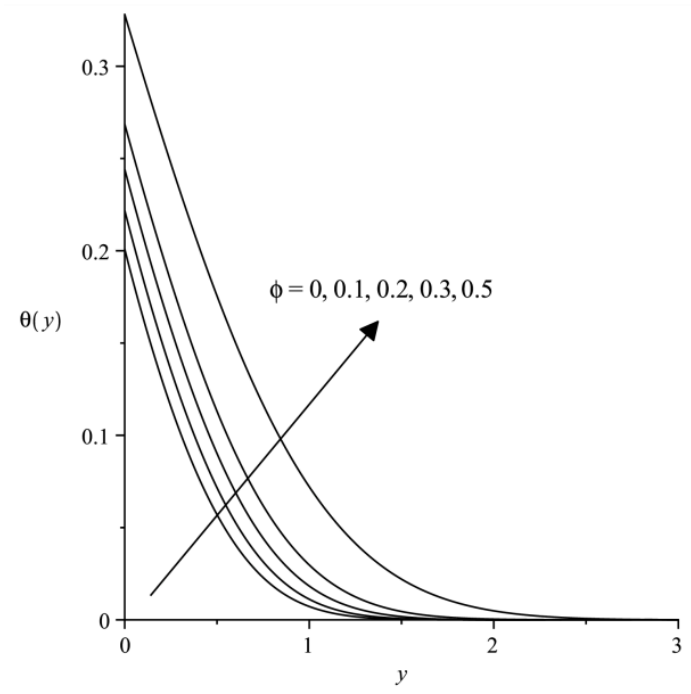

Fig. 5. Variation of $\theta(y)$ due to $\phi$ 


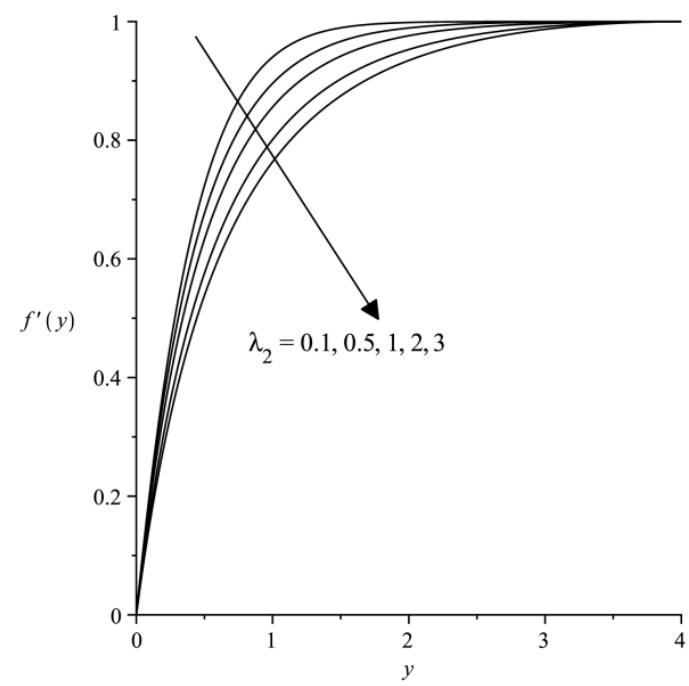

Fig. 6. Variation of $f^{\prime}(y)$ due to $\lambda_{2}$

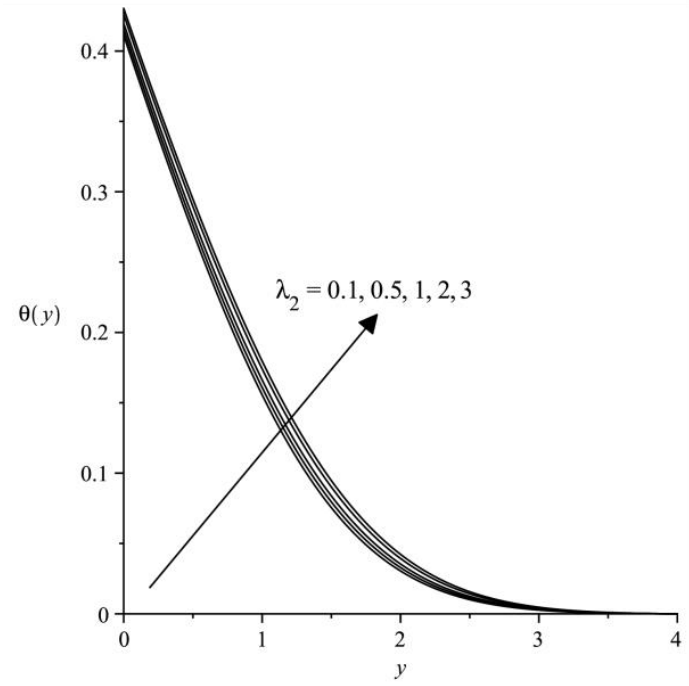

Fig. 7. Variation of $\theta(y)$ due to $\lambda_{2}$

\section{Conclusions}

A detailed theoretical study concentrating on the Jeffrey nanofluid flow over a horizontal circular cylinder near the lower stagnation point with suction/injection, mixed convection and convective boundary conditions has been deliberated. Copper $(\mathrm{Cu})$ and Carboxymethyl cellulose solution (CMC) were selected to be the nanoparticles and base fluid, respectively. The resulting ordinary differential equations were subsequently tackled via the Runge-Kutta Fehlberg method (RKF 45). The benchmark of the solution is attained by way of comparison with limiting cases of existing publications. The results were perceived to be in an excellent consistency. Summarization of the present findings can be outlined as below

i. $\quad$ Velocity rises but temperature reduces as $f_{w}$ escalates.

ii. Both velocity and temperature are increased as $\phi$ intensifies.

iii. Velocity declines while temperature upsurges as $\lambda_{2}$ augments.

\section{Acknowledgement}

The authors wish to thank the Universiti Malaysia Pahang (UMP) for the provision given via research grants RDU190356 and RDU1901124 (FRGS/1/2019/STG06/UMP/02/1).

\section{References}

[1] Al-Sanea, Sami A. "Mixed convection heat transfer along a continuously moving heated vertical plate with suction or injection." International Journal of Heat and Mass Transfer 47, no. 6-7 (2004): 1445-1465. https://doi.org/10.1016/i.ijheatmasstransfer.2003.09.016

[2] Chaudhary, M. A., and J. H. Merkin. "The effects of blowing and suction on free convection boundary layers on vertical surfaces with prescribed heat flux." Journal of Engineering Mathematics 27, no. 3 (1993): 265-292. https://doi.org/10.1007/BF00128967

[3] Arifin, Nur Syamilah, Syazwani Mohd Zokri, Abdul Rahman Mohd Kasim, Mohd Zuki Salleh, Wan Nur Syahidah Wan Yusoff, Nurul Farahain Mohammad, and Sharidan Shafie. "Aligned magnetic field on dusty Casson fluid over a stretching sheet with Newtonian heating." Malaysian Journal of Fundamental and Applied Sciences 13, no. 3 (2017): 245-248. https://doi.org/10.11113/mjfas.v13n3.592

[4] Zokri, Syazwani Mohd, Nur Syamilah Arifin, Muhammad Khairul Anuar Mohamed, Abdul Rahman Mohd Kasim, Nurul Farahain Mohammad, and Mohd Zuki Salleh. "Influence of viscous dissipation on the flow and heat transfer 
of a Jeffrey fluid towards horizontal circular cylinder with free convection: A numerical study." Malaysian Journal of Fundamental and Applied Sciences 14, no. 1 (2018): 40-47.

[5] Mustafa, Meraj, A. Mushtaq, Tasawar Hayat, and Ahmed Alsaedi. "Non-aligned MHD stagnation-point flow of upper-convected Maxwell fluid with nonlinear thermal radiation." Neural Computing and Applications 30, no. 5 (2018): 1549-1555. https://doi.org/10.1007/s00521-016-2761-2

[6] Kumar, Kempannagari Anantha, JV Ramana Reddy, Vangala Sugunamma, and Naramgari Sandeep. "MHD flow of chemically reacting Williamson fluid over a curved/flat surface with variable heat source/sink." International Journal of Fluid Mechanics Research 46, no. 5 (2019).

https://doi.org/10.1615/InterJFluidMechRes.2018025940

[7] Ashraf, M. Bilal, Tasawar Hayat, Sabir Ali Shehzad, and Bilal Ahmed. "Thermophoresis and MHD mixed convection three-dimensional flow of viscoelastic fluid with Soret and Dufour effects." Neural Computing and Applications 31, no. 1 (2019): 249-261.

https://doi.org/10.1007/s00521-017-2997-5

[8] Hayat, Tasawar, Sumaira Qayyum, Maria Imtiaz, and Ahmed Alsaedi. "Impact of Cattaneo-Christov heat flux in Jeffrey fluid flow with homogeneous-heterogeneous reactions." PloS one 11, no. 2 (2016): e0148662.

https://doi.org/10.1371/journal.pone.0148662

[9] Choi, Stephen US, and Jeffrey A. Eastman. Enhancing thermal conductivity of fluids with nanoparticles. No. ANL/MSD/CP-84938; CONF-951135-29. Argonne National Lab., IL (United States), 1995.

[10] Pal, Dulal, and Gopinath Mandal. "Thermal radiation and MHD effects on boundary layer flow of micropolar nanofluid past a stretching sheet with non-uniform heat source/sink." International Journal of Mechanical Sciences 126 (2017): 308-318.

https://doi.org/10.1016/i.ijmecsci.2016.12.023

[11] Lu, Dianchen, M. Ramzan, Shafiq Ahmad, Jae Dong Chung, and Umer Farooq. "A numerical treatment of MHD radiative flow of Micropolar nanofluid with homogeneous-heterogeneous reactions past a nonlinear stretched surface." Scientific Reports 8, no. 1 (2018): 1-17. https://doi.org/10.1038/s41598-018-30965-x

[12] Kumam, Poom, Zahir Shah, Abdullah Dawar, Haroon Ur Rasheed, and Saeed Islam. "Entropy generation in MHD radiative flow of CNTs Casson nanofluid in rotating channels with heat source/sink." Mathematical Problems in Engineering 2019 (2019). https://doi.org/10.1155/2019/9158093

[13] Merkin, J. H. "Mixed convection from a horizontal circular cylinder." International Journal of Heat and Mass Transfer 20, no. 1 (1977): 73-77. https://doi.org/10.1016/0017-9310(77)90086-2

[14] Aldoss, T. K., Y. D. Ali, and M. A. Al-Nimr. "MHD mixed convection from a horizontal circular cylinder." Numerical Heat Transfer, Part A Applications 30, no. 4 (1996): 379-396.

https://doi.org/10.1080/10407789608913846

[15] Aldos, T. K., and Y. D. Ali. "MHD free forced convection from a horizontal cylinder with suction and blowing." International Communications in Heat and Mass Transfer 24, no. 5 (1997): 683-693. https://doi.org/10.1016/S0735-1933(97)00054-7

[16] Nazar, Roslinda, Norsarahaida Amin, and loan Pop. "Mixed convection boundary-layer flow from a horizontal circular cylinder in micropolar fluids: case of constant wall temperature." International Journal of Numerical Methods for Heat \& Fluid Flow 13, no. 1 (2003): 86-109.

https://doi.org/10.1108/09615530310456778

[17] Nazar, Roslinda, Norsarahaida Saidina Amin, and loan Pop. "Mixed convection boundary layer flow from a horizontal circular cylinder in a micropolar fluid: Case of constant wall heat flux." International Journal of Fluid Mechanics Research 31, no. 2 (2004): 1-17. https://doi.org/10.1615/InterJFluidMechRes.v31.i2.40

[18] Anwar, llyana, Norsarahaida Amin, and loan Pop. "Mixed convection b oundary layer flow of a viscoelastic fluid over a horizontal circular cylinder." International Journal of Non-Linear Mechanics 43, no. 9 (2008): 814-821. https://doi.org/10.1016/j.ijnonlinmec.2008.04.008

[19] Ahmad, Syakila, Norihan M. Arifin, Roslinda Nazar, and loan Pop. "Mixed convection boundary layer flow past an isothermal horizontal circular cylinder with temperature-dependent viscosity." International Journal of Thermal Sciences 48, no. 10 (2009): 1943-1948. https://doi.org/10.1016/i.ijthermalsci.2009.02.014

[20] Salleh, Mohd Zuki, Roslinda Nazar, and Ioan Pop. "Mixed convection boundary layer flow over a horizontal circular cylinder with Newtonian heating." Heat and Mass Transfer 46, no. 11-12 (2010): 1411-1418. 
https://doi.org/10.1007/s00231-010-0662-y

[21] Nazar, R., L. Tham, I. Pop, and D. B. Ingham. "Mixed convection boundary layer flow from a horizontal circular cylinder embedded in a porous medium filled with a nanofluid." Transport in Porous Media 86, no. 2 (2011): 517536. https://doi.org/10.1007/s11242-010-9637-1

[22] Tham, Leony, Roslinda Nazar, and loan Pop. "Mixed convection boundary layer flow from a horizontal circular cylinder in a nanofluid." International Journal of Numerical Methods for Heat \& Fluid Flow 22, no. 5 (2012): 576 606.

https://doi.org/10.1108/09615531211231253

[23] Kasim, Abdul Rahman Mohd, Nurul Farahain Mohammad, Sharidan Shafie, and loan Pop. "Constant heat flux solution for mixed convection boundary layer viscoelastic fluid." Heat and Mass Transfer 49, no. 2 (2013): 163-171. https://doi.org/10.1007/s00231-012-1075-x

[24] Mohamed, Muhammad Khairul Anuar, Mohd Zuki Salleh, Nor Aida Zuraimi Md Noar, and Anuar Ishak. "The viscous dissipation effects on the mixed convection boundary layer flow on a horizontal circular cylinder." Jurnal Teknologi 78, no. 4-4 (2016): 73-79.

https://doi.org/10.11113/jt.v78.8304

[25] Mohamed, Muhammad Khairul Anuar, Norhafizah Md Sarif, Nor Aida Zuraimi Md Noar, Mohd Zuki Salleh, and Anuar Mohd Ishak. "Mixed convection boundary layer flow on a horizontal circular cylinder in a nanofluid with viscous dissipation effect." Malaysian Journal of Fundamental and Applied Sciences 14, no. 1 (2018): 32-39.

[26] Zokri, Syazwani Mohd, Nur Syamilah Arifin, Muhammad Khairul Anuar Mohamed, Abdul Rahman Mohd Kasim, Nurul Farahain Mohammad, and Mohd Zuki Salleh. "Mathematical model of mixed convection boundary layer flow over a horizontal circular cylinder filled in a Jeffrey fluid with viscous dissipation effect." Sains Malaysiana 47, no. 7 (2018): 1607-1615. https://doi.org/10.17576/ism-2018-4707-32

[27] Mahat, Rahimah, Noraihan Afiqah Rawi, Abdul Rahman Mohd Kasim, and Sharidan Shafie. "Mixed convection flow of viscoelastic nanofluid past a horizontal circular cylinder with viscous dissipation." Sains Malaysiana 47, no. 7 (2018): 1617-1623. https://doi.org/10.17576/ism-2018-4707-33

[28] Lin, Yanhai, Liancun Zheng, and Xinxin Zhang. "Radiation effects on Marangoni convection flow and heat transfer in pseudo-plastic non-Newtonian nanofluids with variable thermal conductivity." International Journal of Heat and Mass Transfer 77 (2014): 708-716. https://doi.org/10.1016/i.ijheatmasstransfer.2014.06.028

[29] Yaşar, Fevzi, Hasan Toğrul, and Nurhan Arslan. "Flow properties of cellulose and carboxymethyl cellulose from orange peel." Journal of Food Engineering 81, no. 1 (2007): 187-199. https://doi.org/10.1016/i.jfoodeng.2006.10.022

[30] Rashad, A. M., A. J. Chamkha, and M. Modather. "Mixed convection boundary-layer flow past a horizontal circular cylinder embedded in a porous medium filled with a nanofluid under convective boundary condition." Computers \& Fluids 86 (2013): 380-388. https://doi.org/10.1016/j.compfluid.2013.07.030 